\title{
Oligodendroglia Regulate the Regional Expansion of Axon Caliber and Local Accumulation of Neurofilaments during Development Independently of Myelin Formation
}

\author{
Ivelisse Sánchez, ${ }^{1,3}$ Linda Hassinger, ${ }^{1}$ Peter A. Paskevich, ${ }^{2}$ H. David Shine, ${ }^{5}$ and Ralph A. Nixon ${ }^{1,3,4}$ \\ 1 Laboratories for Molecular Neuroscience, ${ }^{2}$ McLean Hospital, ${ }^{3}$ Department of Psychiatry, and 4 Program in Neuroscience, \\ Harvard Medical School, Belmont, Massachusetts 02178, and 5Department of Neurosurgery and Cell Biology, Baylor \\ College of Medicine, Houston, Texas 77030
}

\begin{abstract}
Axon caliber may be influenced by intrinsic neuronal factors and extrinsic factors related to myelination. To understand these extrinsic influences, we studied how axon-caliber expansion is related to changes in neurofilament and microtubule organization as axons of retinal ganglion cells interact with oligodendroglia and become myelinated during normal mouse brain development. Caliber expanded and neurofilaments accumulated only along regions of the axon invested with oligodendroglia. Very proximal portions of axons within a region of the optic nerve from which oligodendrocytes are excluded remained unchanged. More distally, these axons rapidly expanded an average of fourfold as soon as they were recruited to become myelinated between postnatal days 9 and 120 . Unmyelinated axons remained unchanged. Axons ensheathed by oligodendroglial processes, but not yet myelinated, were
\end{abstract}

intermediate in caliber and neurofilament number. That oligodendrocytes can trigger regional caliber expansion in the absence of myelin was confirmed using three strains of mice with different mutations that prevent myelin formation but allow wrapping of some axons by oligodendroglial processes. Unmyelinated axons persistently wrapped by oligodendrocytes showed full axon caliber expansion, neurofilament accumulation, and appropriately increased lateral spacing between neurofilaments. Thus, signals from oligodendrocytes, independent of myelin formation, are sufficient to induce full axon radial growth primarily by triggering local accumulation and reorganization of the neurofilament network.

Key words: neurofilaments; oligodendroglia; myelin; axon caliber; CNS development; optic nerve
Once axons reach their targets and form synapses, further maturation often involves marked radial growth, changes in cytoskeleton composition and organization, and ensheathment by myelin. Essential to axon radial growth are neurofilaments, $10 \mathrm{~nm}$ intermediate filaments composed of three subunits, NF-L, NF-M, and NF-H, with apparent molecular masses of approximately 70, 150, and $200 \mathrm{kDa}$, respectively (Shaw, 1982). Two observations firmly establish this point. A mutation in the Japanese quail that interferes with NF-L synthesis prevents both filament assembly (Ohara et al., 1993) and radial axon growth (Sakaguchi et al., 1993). In a Lac-Z NF-H transgenic mouse, neurofilament transport into axons is selectively blocked and radial growth is substantially reduced (Eyer and Peterson, 1994). Important questions remain, however, about how the number of neurofilaments in axons is regulated and what signals instruct axons to grow to a particular size.

As developing axons grow radially, the gene expression and synthesis of neurofilaments increase and axonal transport rates for cytoskeletal proteins slow (Willard and Siman, 1983; Hoffman et al., 1984, 1985a). Neurofilaments also become extensively phosphorylated (Carden et al., 1985, 1987; Dahl et al., 1986), leading

Received Feb. 20, 1996; revised April 30, 1996; accepted May 22, 1996.

This research was supported by Grant AG05604 from the National Institute on Aging. We thank Drs. Emil Adamec, Charissa Dyer, and Brian Cummings for valuable comments and help in the statistical analysis of these data. We are grateful to Bob Hassinger for help in the preparation of figures, and to Johanne Khan for typing and assistance with manuscript preparation.

Correspondence should be addressed to Dr. Ivelisse Sánchez, Laboratories for Molecular Neuroscience, McLean Hospital, 115 Mill Street, Belmont, MA 02178. Copyright (C) 1996 Society for Neuroscience $0270-6474 / 96 / 165095-11 \$ 05.00 / 0$ to local retention and accumulation of neurofilaments within a stationary axonal network (Nixon, 1992; Nixon et al., 1994a), a lowered susceptibility of neurofilaments to calpains (Goldstein et al., 1987; Pant, 1988), and increases their lateral spacing (Geisler et al., 1983; Hsieh et al., 1994; Nixon et al., 1994b). The relative contributions of these synthetic and local post-translational mechanisms to caliber growth have not been extensively investigated.

Recently, myelin has been shown to influence the caliber of mature axons and their radial growth during development (Cole et al., 1994; Colello and Schwab, 1994; Hsieh et al., 1994; Nixon et al., 1994b). In addition, the modulation of axonal caliber by myelin seems to be linked to changes in the phosphorylation state and dynamic behaviors of neurofilaments (DeWaegh and Brady, 1990; Reles and Friede, 1991; Mata et al., 1992; Nixon et al., 1994a). Still unknown, however, is whether myelin provides the actual signals required for axonal growth, and which aspects of neurofilament behavior are regulated by these signals are unknown.

In this study, we investigated the influence of oligodendroglia on caliber expansion and the neurofilament network in normal unperturbed retinal ganglion cell neurons of mice throughout postnatal development. We analyzed axons during the period of myelination in the portion of the optic nerve that is destined to acquire myelin and the portion that remains unmyelinated, in addition to the small population of optic axons (5-10\%) that remain unmyelinated along their entire length. Finally, to define the relative importance of myelin and developing glia cells on axon maturation, we analyzed three strains of mutant mice; shiverer (Chernoff, 1981), myelin-synthesis deficiency allele of jimpy 
(Meier and MacPike, 1970), and quaking (Sidman et al., 1964). These strains harbor mutations of myelin basic protein (Roach et al., 1983), myelin proteolipid protein (Phillips, 1954), and an unknown protein (Campagnoni, 1988), respectively. These mutations prevent myelin formation on most CNS axons but enable oligodendroglia to mature to varying degrees (Nave, 1994). Together, these studies establish that regional caliber growth, local neurofilament accumulation, and interneurofilament spacing are regulated by extrinsic glial signals and that myelin formation is not required for axons to achieve full-caliber expansion and regional neurofilament accumulation.

\section{MATERIALS AND METHODS}

Animals. The (jp ${ }^{\mathrm{msd}}$ ) myelin synthesis deficiency mutant, an allele of the jimpy mutation and quaking, an independent autosomal mutation (Sidman et al., 1964), was maintained on a $\mathrm{C} 57 \mathrm{Bl} / 6 \mathrm{~J} / \mathrm{C} 3 \mathrm{H}$ hybrid background. Shiverer mutant mice (Doolittle et al., 1977) were maintained on a DBA/2J genetic background. Crossing mice homozygous for shi and normal DBA/2J mice produced heterozygous shi mice $(+/$ shi $)$, which exhibit 50\% of normal MBP expression (Shine et al., 1992). C57Bl/6J mice ages 9-120 d were used in studies of normal development. Breeding and tissue dissections were performed as described previously (Nixon and Logvinenko, 1986).

Electron microscopy. Mice were anesthetized with halothane gas, and tissue fixative was achieved through intracardial perfusion with $4 \%$ paraformaldehyde $/ 5 \%$ glutaraldehyde in $0.1 \mathrm{M} \mathrm{PBS}, \mathrm{pH} 7.4$, at room temperature. The retina and optic nerve then were dissected, post-fixed in $1 \%$ phosphate saline buffered osmium tetroxide containing $0.8 \% \mathrm{KFeCN}_{2}$ and dehydrated through an ethanol series (Nixon et al., 1994a). The tissue, segmented in $1.2 \mathrm{~mm}$ pieces, was cleared in propylene oxide and embedded in Medcast (Ted Pella, Tustin, CA). Ultrathin sections were collected every $0.25 \mu \mathrm{m}$ until a section was reached that contained the retinal excavation surrounded by retinal tissue. The initial appearance of the most distal aspect of the retinal excavation was used as a standard reference point. The ultrathin sections were stained with uranyl acetate and lead citrate and examined in a JEOL JEM1200 EX electron microscope at $80 \mathrm{kV}$.

Axonal cross-sectional determination. The cross-sectional areas of 15613919 axon profiles were quantified in mice at each of six postnatal ages. Two levels of the optic nerve, 50 and $700 \mu \mathrm{m}$ from the retinal excavation point, were examined for every given age. Where multiple mice were analyzed [postnatal days (P) 16, 30, and 120], axonal area distribution and neurofilament-microtubule numbers (see below) differed less than $5 \%$ among animals. Axonal fields were selected evenly from all regions of the cross-section, using the mesh gridbars as superimposed divisional landmarks. Populations of more than 500 randomly selected axons have been shown to represent accurately the total optic axon population (Nixon and Logvinenko, 1986). Ten nonoverlapping microscopic fields from each level were photographed at low power and printed at a final magnification of 18,000×. All axons from each field were measured unless the angle of transection was clearly oblique, which occurred in less than $5 \%$ of the population. In some experiments, myelinated, oligodendrocyte-wrapped, and unmyelinated fibers were analyzed separately. Wrapped fibers were defined as those profiles completely surrounded by oligodendrocyte cytoplasmic processes, but devoid of myelin. Similarly, the cross-sectional areas of 1598-3247 axon profiles from each animal within a group of mutant mice, including shiverer homozygote and heterozygote, quaking, and myelin synthesis deficient (msd) mice, were determined. Axonal areas were measured using an IBM-compatible computer with Bioquant ( $\mathrm{R}$ and $\mathrm{M}$ Biometrics) software and a Summagraphics supergrid digitizing tablet peripheral. Histograms were constructed from the resultant data. The percentage of axons in each of a series of equally spaced size categories was determined at six of the postnatal ages. Histograms were constructed by plotting these percentages as a function of axonal crosssectional area.

Neurofilament and microtubule quantification. At each of six postnatal ages, the numbers of neurofilaments and microtubules were determined from 300-600 axon profiles collectively displaying the same axonal area distribution histogram as the total axon population in the optic nerve at the appropriate axonal level (e.g., 50 or $700 \mu \mathrm{m}$ ). To compare data sets from different postnatal ages, a single value for the absolute number of neurofilaments or microtubules contained within 1000 axons of sizes representative of the total fixed population was calculated for each of the postnatal ages analyzed. The complete analysis was duplicated in a second mouse at P16, P30, and P120. No statistically significant differences between duplicates were observed $(<10 \%$ variation) for any parameter analyzed in this study. Morphometric analysis was performed using a compatible IBM computer and Bioquant software as described by Nixon et al. (1994). A total of 100,800 neurofilaments and 72,151 microtubules were counted in 4444 axons in the developmental study, and a total of 84,390 neurofilaments and 44,002 microtubules were counted in 1738 axons in the myelin mutant analyses. The $x$-axis in all line graphs depicting data at varying postnatal ages was plotted using logarithmic scale.

Neurofilament nearest-neighbor analysis. Interneurofilament distances were determined in 25-40 axon profiles representative of the axonal total population in the optic nerve. The distances between neurofilaments in each axon were determined using a digitizing tablet and a program especially designed for this purpose (P. Paskevich, unpublished observations). The distances between neurofilament pairs were expressed as a percentage of the total neurofilament pairs analyzed and sorted in $1 \mathrm{~nm}$ bins to determine the mean interneurofilament distance of $95 \%$ of the total number of neurofilament pairs, and in $5 \mathrm{~nm}$ bins for graphical demonstration. In the developmental and mutant studies, 267-1466 and 739-4681 neurofilaments, respectively, were analyzed. The limitations of the analysis system were established by repeated determinations of the same set of profiles, which yielded a variation of $0.96 \pm 0.53 \mathrm{~nm}$ for 1565 neurofilaments counted.

Statistical analysis. All data sets showed nonparametric distributions as demonstrated by the Shapiro-Wilk test. The analysis of variance was performed by the Wilcoxon/Kruskal-Wallis test with $p \leq 0.05$, demonstrating significant differences among the groups analyzed. The TukeyKramer-HSD test was used to describe significant differences between specific axonal populations (JMP software). In the latter test, $p>0$ demonstrates statistical significance.

\section{RESULTS \\ Caliber expands regionally along optic axons during development}

A dense layer of astrocytes, known as the lamina cribrosa, is located $100-150 \mu \mathrm{m}$ from the retinal excavation, the point where intraretinal portions of ganglion cell axons converge to form the optic nerve (Fig. 1A) (Nixon et al., 1994b). The lamina cribrosa forms a barrier to oligodendroglia migration into the eye (Perry and Lund, 1990) and, therefore, serves as a boundary between a proximal unmyelinated portion of the ganglion cell axon and a long distal portion of the axon within the optic nerve and tract that may become myelinated (Fig. $1 A$ ). To compare the developmental changes affecting unmyelinated and myelinated regions of the same axons, we measured caliber sizes of very large populations of optic axons at a level of the optic nerve immediately proximal to the lamina cribrosa situated $50 \mu \mathrm{m}$ from the retinal excavation (Fig. $1 B, D$ ), and a level distal to this structure, located $700 \mu \mathrm{m}$ from the retinal excavation (Fig. $1 C, E$ ). At P9, the morphologies of axons at both levels (Fig. $1 B$ vs $1 C$ ) were similar, except for the presence of myelin on a few $(<1 \%)$ of the axons at the $700 \mu \mathrm{m}$ level. As development progressed, however, differences between the two levels became striking (Fig. $1, C^{\prime}$, vs $E^{\prime}$ ). These morphological differences were quantified by measuring the crosssectional areas of axons in representative populations of 10001500 axons at each level and developmental age (Fig. 2). Axon cross-sectional areas for the total populations, grouped according to different size ranges (Fig. 2), demonstrate a progressive significant shift toward groups with larger areas at the $700 \mu \mathrm{m}$ level but not at $50 \mu \mathrm{m}$ level (Tukey-Kramer test). This process began with the growth of a few axons by P12, proceeded to involve most axons between P12 and P30, and ultimately involved $>90 \%$ of the optic axon population by adulthood (Fig. 2). To quantify the changes in average axon size across all developmental ages and allow comparisons with changes in neurofilament number, we calculated the 

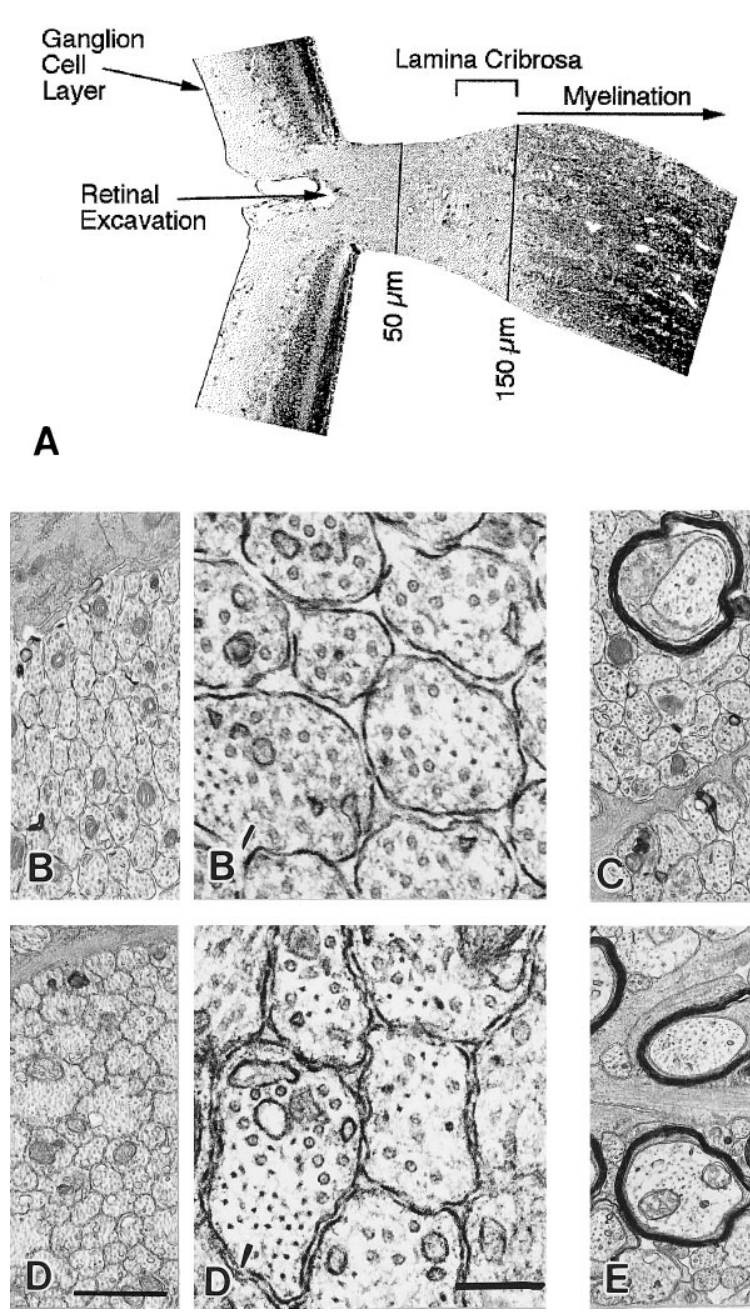
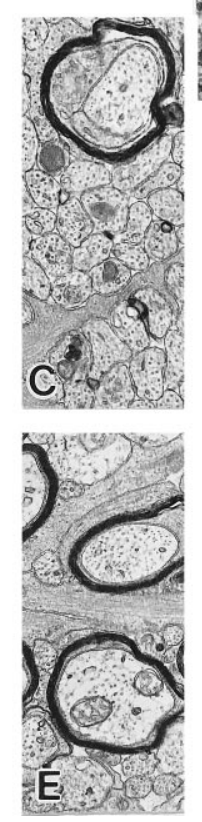

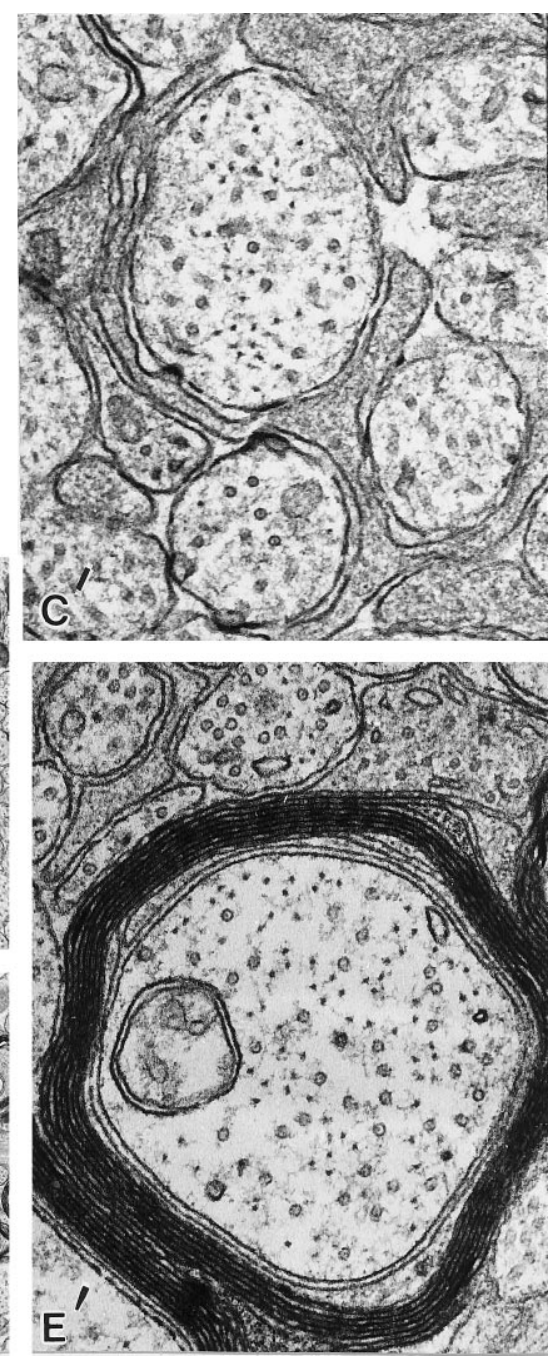

Figure 1. Landmarks of the retino-optic junction $(A)$ and ultrastructural appearance of axons at representative levels of the optic nerve of mice at age 9 and $16 \mathrm{~d}$ $(B-E)$. Distances along the optic nerve referred to in this study were determined relative to the retinal excavation point $(50$ and $700 \mu \mathrm{m})(A)$. The lamina cribrosa begins at $100 \mu \mathrm{m}$ and ends at $150-200$ $\mu \mathrm{m}$, which marks the level along optic axons where myelin ensheathment occurs (bracketed). $B, B^{\prime}$ and $D, D^{\prime}$ denote a proximal axonal level $(50 \mu \mathrm{m})$ at $\mathrm{P} 9$ and P16, respectively. A more distal level (700 $\mu \mathrm{m})$ of a similar population of axons at $\mathrm{P} 9$ and $\mathrm{P} 16$ is shown in $C, C^{\prime}$ and $E, E^{\prime}$. Magnification of micrographs in $B-E$ and $B^{\prime}-E^{\prime}$ is represented by scale bars in $D(1$ $\mu \mathrm{m})$ and $D^{\prime}(0.2 \mu \mathrm{m})$, respectively. total cross-sectional areas for populations of 1000 axons identical in caliber distribution to those depicted in Figure 2. As shown in Figure 3, calibers changed minimally at the $50 \mu \mathrm{m}$ level, but the same axons underwent an average fourfold caliber expansion more distally (Wilcoxon/Kruskal-Wallis, $p=0.21$ ).

\section{Regional caliber expansion is temporally and spatially related to local neurofilament accumulation as axons are recruited for myelination}

Like axon caliber, the organization of neurofilaments during development was regulated differently at axonal levels proximal or distal to the lamina cribrosa. The number of neurofilaments at the $50 \mu \mathrm{m}$ level was similar at P9 and adulthood and varied $<50 \%$ at intermediate developmental ages (data not shown). More distally, neurofilament numbers rose nearly fourfold between P9 and P30 in parallel to changes in axon caliber (Fig. 4, top). The microtubule number gradually rose only 2 - to 2.5 -fold. The early rise was similar at the 50 and $700 \mu \mathrm{m}$ levels, but after P21, microtubules increased an additional $50 \%$ at $700 \mu \mathrm{m}$ only (data not shown). The difference in microtubule numbers at these two levels, which confirmed previous estimations in adult mice (Nixon et al., 1994a), was, however, a minimal contribution to regional caliber growth compared with the fourfold rise in neurofilaments. Even during early postnatal ages, the total number of microtubules and neurofilaments required to achieve a given caliber size was greater at 50 than at $700 \mu \mathrm{m}$, as observed previously in the adult mice, implying that additional locally regulated factors may be involved in radial growth irrespective of developmental stage (data not shown).

Because caliber expanded and neurofilaments accumulated only in regions of the optic nerve destined to become myelinated, we investigated the relationship between radial growth and the appearance of myelin on individual optic axons. Initial caliber expansion of a small subset of axons at P12 coincided with appearance of the first myelinated axons; additional expansion within the axon population occurred in exact proportion to the rise in numbers of myelinated fibers (Fig. 4, top). Developmentally regulated changes in axons that may be either dependent on or independent of myelination were distinguished by analyzing the myelinated and unmyelinated fiber populations separately. Axons that were unmyelinated and not contacted directly by an oligodendrocyte showed negligible regional caliber expansion or increase in neurofilament number (Fig. 4, bottom). During ages of extensive recruitment of axons for myelination, the caliber distribution of the unmyelinated axon population was not altered, indicating that axons of a particular size were not selectively recruited (Fig. 5) (Tukey-Kramer, $p=-0.004$ ). By contrast, myelinated fibers, regardless of postnatal age, exhibited the same average caliber and neurofilament number as fully mature axons 


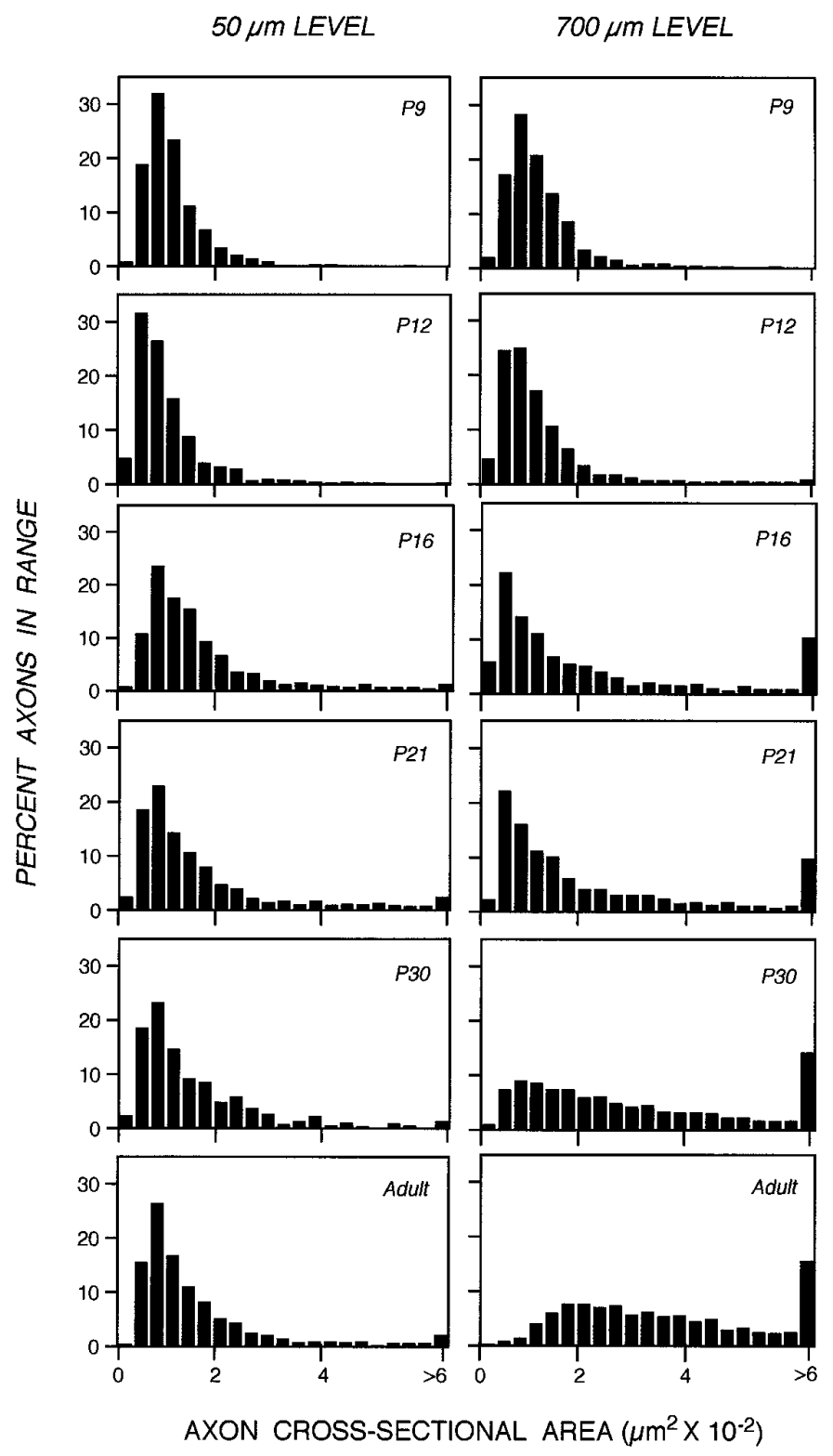

Figure 2. Distribution of axon calibers expressed as cross-sectional areas along developing optic nerves, 50 or $700 \mu \mathrm{m}$ from the eye. The percentage of axons within a particular size range is shown, at the indicated postnatal ages, for a total of 7182 axons at the $50 \mu \mathrm{m}$ level and for 10,145 axons at the $700 \mu \mathrm{m}$ level. At all postnatal ages, the axonal cross-sectional area distributions at the 50 and $700 \mu \mathrm{m}$ optic nerve levels differ significantly (Kruskal-Wallis test, $p=0.010$ ).

(Figs. 4, 5). These results show that caliber expansion for the total optic axon population is determined by the rate at which fibers are recruited to become myelinated. The data indicate further that the process of caliber expansion must be rapid. For example, between $\mathrm{P} 21$ and $\mathrm{P} 30,>50 \%$ of the optic axon population became myelinated (Fig. 4, top), which is equivalent to $\sim 6000$ axons per day. If the expansion process had required more than $24 \mathrm{hr}$, fibers at intermediate stages of expansion would have been sufficiently numerous to lower the average caliber of the myelinated fiber population below the value obtained for mature mice. This was not observed.

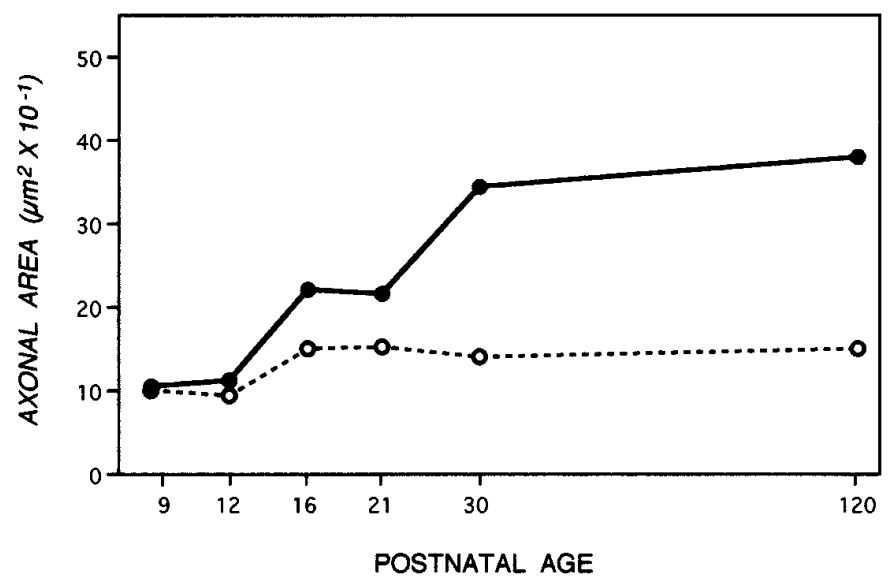

Figure 3. Axon caliber changes during development at optic nerve levels $50 \mu \mathrm{m}$ (open circles) and $700 \mu \mathrm{m}$ (filled circles) from the eye. To allow similar axon populations at each level to be compared, cross-sectional areas of axons at each level were expressed as a total area per 1000 axons of sizes representative of the entire optic nerve population at that level. Each data point represents the cross-sectional area determination from 510-1717 axons at $50 \mu \mathrm{m}$ (open circle) and 1282-2413 axons at the $700 \mu \mathrm{m}$ level (filled circle) at each postnatal age. All SEM for these data are smaller than the width of the points.

\section{Interneurofilament spacing is locally controlled}

The distances between most neurofilaments and their nearest neighbors are nonrandom in mature axons (Hsieh et al., 1994; Nixon et al., 1994a). To investigate developmental influences on interneurofilament spacing, we carried out morphometric analyses at six postnatal ages on groups of 25-40 axons exhibiting a range of caliber sizes representative of the caliber distribution within the total optic axon population. For each neurofilament in these axons, the distance to its nearest neighbor was measured. Like caliber and neurofilament number, the spacing between neurofilaments was locally controlled, increasing only at the 700 $\mu \mathrm{m}$ level (Fig. 6). At the $50 \mu \mathrm{m}$ axonal level, interneurofilament distances assumed a relatively narrow unimodal distribution, showing that most neurofilaments were situated $25-35 \mathrm{~nm}$ from their nearest neighbor at all ages between P9 and P120. The minimum spacing $(15-20 \mathrm{~nm})$ did not change appreciably. At 700 $\mu \mathrm{m}$, axons at any postnatal age, once myelinated, contained neurofilaments spaced similarly to those of adult myelinated fibers (Tukey-Kramer, $p<0$ ), whereas the spacing between neurofilaments in unmyelinated axons continued to increase during development (Wilcoxon/Kruskal-Wallis, $p=0.010$ ). On average, interneurofilament distances were 1.7-fold larger at $700 \mu \mathrm{m}(54.7 \pm$ $17.9 \mathrm{~nm})$ than at the $50 \mu \mathrm{m}$ level $(33 \pm 9.18 \mathrm{~nm})$. Although a greater range of nearest-neighbor distances was seen at 700 than at $50 \mu \mathrm{m}$, the distribution still was unimodal. Fibers that were not yet myelinated remained immature in caliber and neurofilament number, but neurofilaments within these axons also displayed increased spacing compared with that at the $50 \mu \mathrm{m}$ level even at P9, confirming previous data in adult optic axons (Nixon et al., 1994b).

\section{Signals from oligodendroglia, not myelin, initiate caliber expansion and neurofilament accumulation}

Although the relationship between myelination and axon maturation appeared to be close, we noticed that some unmyelinated axons were ensheathed by an oligodendroglial process, and these 


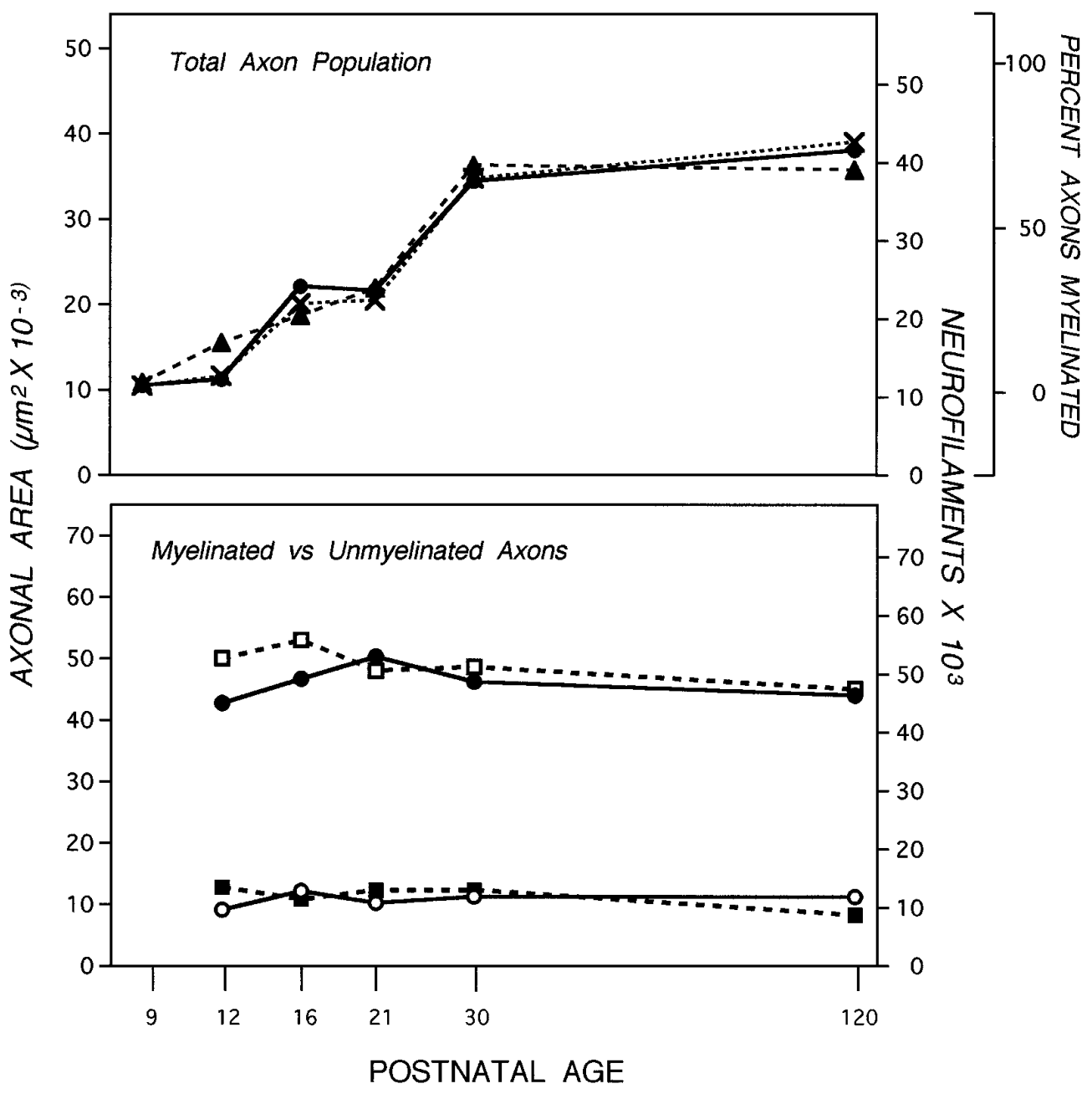

Figure 4. Effect of myelination on axonal area and neurofilament accumulation. Top, The cross-sectional areas of axons at the $700 \mu \mathrm{m}$ level (filled circles), the percentage $(X)$ of myelinated axons (see Fig. 3), and the number of neurofilaments (filled triangles) in the total population of axons was determined. The cross-sectional areas $\left(\mu \mathrm{m}^{2}\right)$ of myelinated (filled circles; $n=3632$ ) and unmyelinated (open circles; $n=6098$ ) axons were determined from electron micrographs at $20,000 \times$ (bottom). Neurofilament numbers in 829 myelinated (open squares) and 1676 unmyelinated (filled squares) axons of caliber sizes representative of the total optic nerve population were determined at the 700 $\mu \mathrm{m}$ axonal level, also included (bottom). SEs are negligible (see Fig. 3). At all postnatal ages, the neurofilament numbers and axonal areas between myelinated and unmyelinated axons differ significantly (Wilcoxon/Kruskal-Wallis, $p=0.01-0.001)$. axons displayed a more mature morphology than their sister axons (Table 1, Fig. 7). These "wrapped" but still unmyelinated axons were considerably more numerous during the period of peak myelination (P21-P30) than at P120, suggesting that they were soon to be myelinated (Table 1). Wrapping by oligodendrocyte processes evidently was a transitory state, because these axons remained a small percentage of the total axon population even between P21 and P30 when $>50 \%$ of axons were becoming myelinated. Despite the transient nature of this stage, these wrapped axons displayed a twofold higher average caliber size and neurofilament content compared with that of other unmyelinated axons (Table 1). The distribution of nearest-neighbor distances was similar to that of the myelinated axon population (data not shown).

\section{Oligodendroglial signals are sufficient to trigger full-caliber expansion}

Because oligodendroglial wrapping is rapidly followed by myelination, we could not assess the relative importance of oligodendrocyte- and myelin-related influences to radial axon growth in normal mice. We, therefore, studied adult mice carrying mutations that block myelination but permit some oligodendroglial cells to mature to varying degrees and ensheathe axons with a cytoplasm-containing oligodendroglial process. Three strains of mice, shiverer (shi/shi), quaking (qk/qk), and jimpy ( $\mathrm{jp}^{\mathrm{msd}} / \mathrm{jp}^{\mathrm{msd}}$ ), carrying mutations of different genes (see introductory remarks), exhibited a similar phenotype in which $89-96 \%$ of optic axons remained unmyelinated (Fig. $7 B$ ), but $6-15 \%$ of these fibers were wrapped by an oligodendroglial process. The latter event, which precedes myelination and is normally brief, is presumably long in duration in these adult mutant mice and, therefore, allowed us to assess the full influence of oligodendroglial signals in the absence of myelin. Under these conditions, unmyelinated axons in contact with an oligodendrocyte achieved the same caliber size and neurofilament number as myelinated axons (Wilcoxon/KruskalWallis, $p=0.2-0.7$ ), which, in turn, exhibited three- to sixfold larger calibers and neurofilament numbers at the $700 \mu \mathrm{m}$ level than at the $50 \mu \mathrm{m}$ level of optic axons (Fig. 8). The range of interneurofilament spacing distances for wrapped axons also was indistinguishable from that of myelinated fibers (Wilcoxon/ Kruskal-Wallis, $p=0.2$ ) (Fig. 9). Thus, unmyelinated axons achieve full regional caliber growth and neurofilament accumulation if ensheathed for a sufficient period of time by an oligodendroglial process.

The unmyelinated fibers in each mouse mutant, on average, also achieved modest local caliber growth (1.6- to 2.0-fold) and neurofilament accumulation (1.1- to 1.4-fold); however, these average increases were principally attributable to a small percentage of axons $(\sim 15 \%)$ having the size of myelinated fibers. The caliber distribution and neurofilament content of the remaining axons ( $66 \%$ of the total shiverer optic axon population) was similar to that of normal unmyelinated fibers and to axons at the $50 \mu \mathrm{m}$ level. This group of atypically large "unmyelinated" axons 
MYELINATED

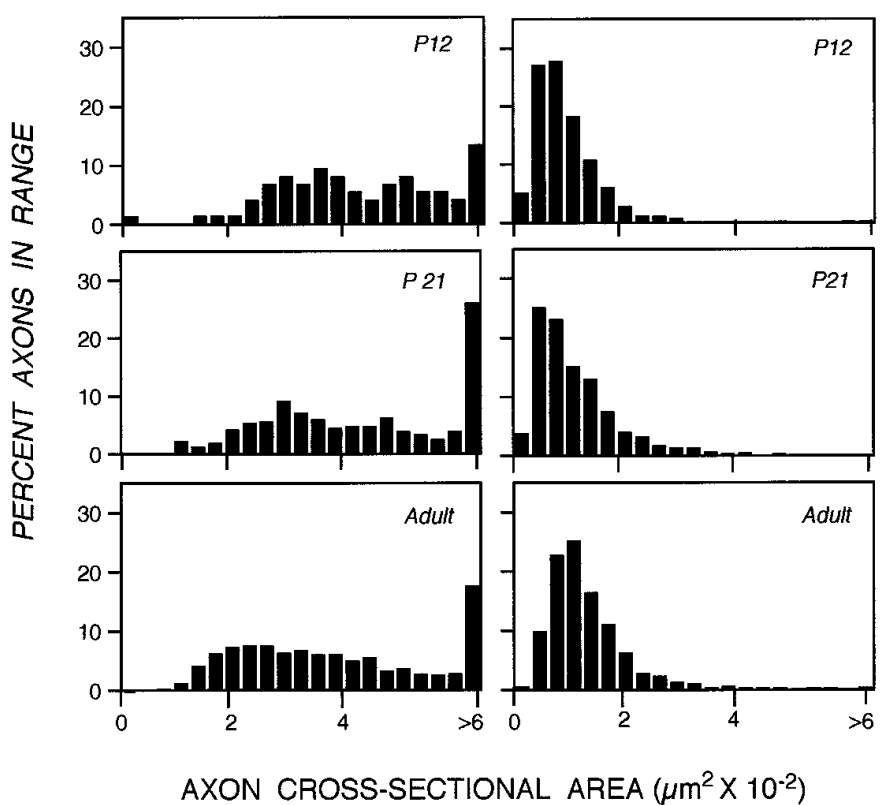

Figure 5. Distribution of cross-sectional areas of myelinated and unmyelinated axonal population at selected postnatal age. The percentage of axons within a size range at each given postnatal age was determined for a total of 1827 myelinated and 2542 unmyelinated axons at the $700 \mu \mathrm{m}$ optic nerve level. The similar cross-sectional area distribution seen at ages just before increased myelination indicates that no subpopulation of unmyelinated axons is preferentially recruited for myelination. Although $>50 \%$ of the unmyelinated axons are recruited for myelination between P21 and P120 (see Fig. 4), their cross-sectional area distributions remain unchanged (Tukey-Kramer, $p=0.003$ ).

is likely to be myelinated at levels immediately above or below the $700 \mu \mathrm{m}$ level analyzed, because some axons from mutant mice were shown to be myelinated in patches along their length (Lachapelle et al., 1990) (R. Nixon, unpublished data). Interneurofilament spacing in unmyelinated fibers of shiverer mutants like that of normal axons was higher at 700 than at $50 \mu \mathrm{m}$ (Fig. 9), but less than that seen in myelinated or oligodendrocyte-wrapped axon populations (Tukey-Kramer test, $p=-0.007,-0.004$, respectively).

\section{DISCUSSION}

\section{The signal for axon caliber expansion during postnatal development is extrinsic}

Using different experimental paradigms, we have shown that the changes in neurofilament dynamics and organization underlying radial axonal growth during postnatal development are locally determined along axons and that only axonal regions contacted by oligodendroglial cells or myelin undergo these changes. Caliber growth and neurofilament accumulation were absent along proximal portions of optic axons from which oligodendroglia but not astrocytes are excluded, along the lengths of normal unmyelinated axons, and along optic axons of mice carrying any one of three different mutations that prevent CNS axons from myelinating. Because at least two of these three mutations affect proteins selectively made by oligodendroglial cells (Campagnoni, 1988), neuronal mechanisms that may be involved in axon radial growth are presumably intact in these mice. That optic axons normally destined to grow postnatally exhibit minimal radial growth in the mutant mice indicates that extrinsic signals, pertaining to oligodendrocytes, are essential for postnatal axon maturation.

The long-standing view that axonal-caliber expansion induces myelination requires reconsideration in light of the present findings and other recent data (Colello et al., 1994). The frequent observation that the first axons to be myelinated tend to be the largest ones in the population (Peters and Vaughn, 1970; Raine, 1984) has fostered this assumption; however, we observed that the caliber distribution of unmyelinated axon changes minimally during postnatal development, indicating that the largest axons are not selectively recruited for myelination. The additional finding that recruited fibers, on average, expand to full size very rapidly may explain why newly myelinated fibers tend to be large. The lack of radial growth at proximal levels of developing optic axons also supports the view that caliber expansion does not precede oligodendrocyte ensheathment of axons and is not completely regulated by intrinsic factors during neuronal differentiation. These findings are consonant with studies of adult transgenic mice expressing the Lac Z-NF-H fusion protein (Eyer and Peterson, 1994) and mutant quail deficient in neurofilaments (Zhao et al., 1995), which show minimal axon caliber expansion despite apparently normal myelination.

Our results add to growing evidence that axon-glial signaling occurs in both directions during postnatal axonal development. Experimentally delaying or disrupting myelination reduces or inhibits axon caliber expansion (Foster et al., 1982; Colello et al., 1994), and components of the myelin sheath influence the outgrowth of axons (Caroni and Schwab, 1989; Colello and Schwab, 1994; Mukhopadhyay et al., 1994). On the other hand, oligodendrocytes compete with astrocytes for growth factors early in development and depend on interactions with axons for their survival (Barres and Raff, 1993). Oligodendroglial proliferation and differentiation and the ability to myelinate are affected by axonal signals that involve electrical impulse conduction along axons (Valat et al., 1988; Kidd et al., 1990; Barres and Raff, 1993; Hardy and Reynolds, 1993) and release of extracellular matrix components (Notterpek and Rome, 1994). In this regard, it is interesting that myelination and radial growth of optic axons are first initiated at P12 when the electroretinogram can first be recorded (Weidman and Kuruabara, 1968).

\section{Local neurofilament accumulation and changes in neurofilament spacing determine the site and extent of radial axon growth}

Accretion of neurofilaments in developing axons has previously been attributed to multiple factors, including increased neurofilament gene expression (Hoffman et al., 1987) and subunit synthesis (Hoffman et al., 1985b), and reduced slow axonal transport rates (Hoffman et al., 1985a). Variations in caliber size also are closely related to changes in neurofilament protein phosphorylation, which promote the local accumulation of neurofilaments within a stationary, but dynamic, axonal network (Lewis and Nixon, 1988; Nixon et al., 1994a; Takeda et al., 1994) and induce neurofilaments to extend sidearms that increase lateral spacing between neurofilaments (DeWaegh et al., 1992; Hsieh et al., 1994; Nixon et al., 1994b; Nakagawa et al., 1995). Our finding that caliber size does not expand in a proximal portion of optic axons proved to be useful in evaluating the possible contributions of these different neurofilament-related variables to axon radial growth. For example, if increased gene expression, synthesis, and transport of neurofilament proteins were major contributions to development of caliber expansion, higher neurofilament numbers would have 


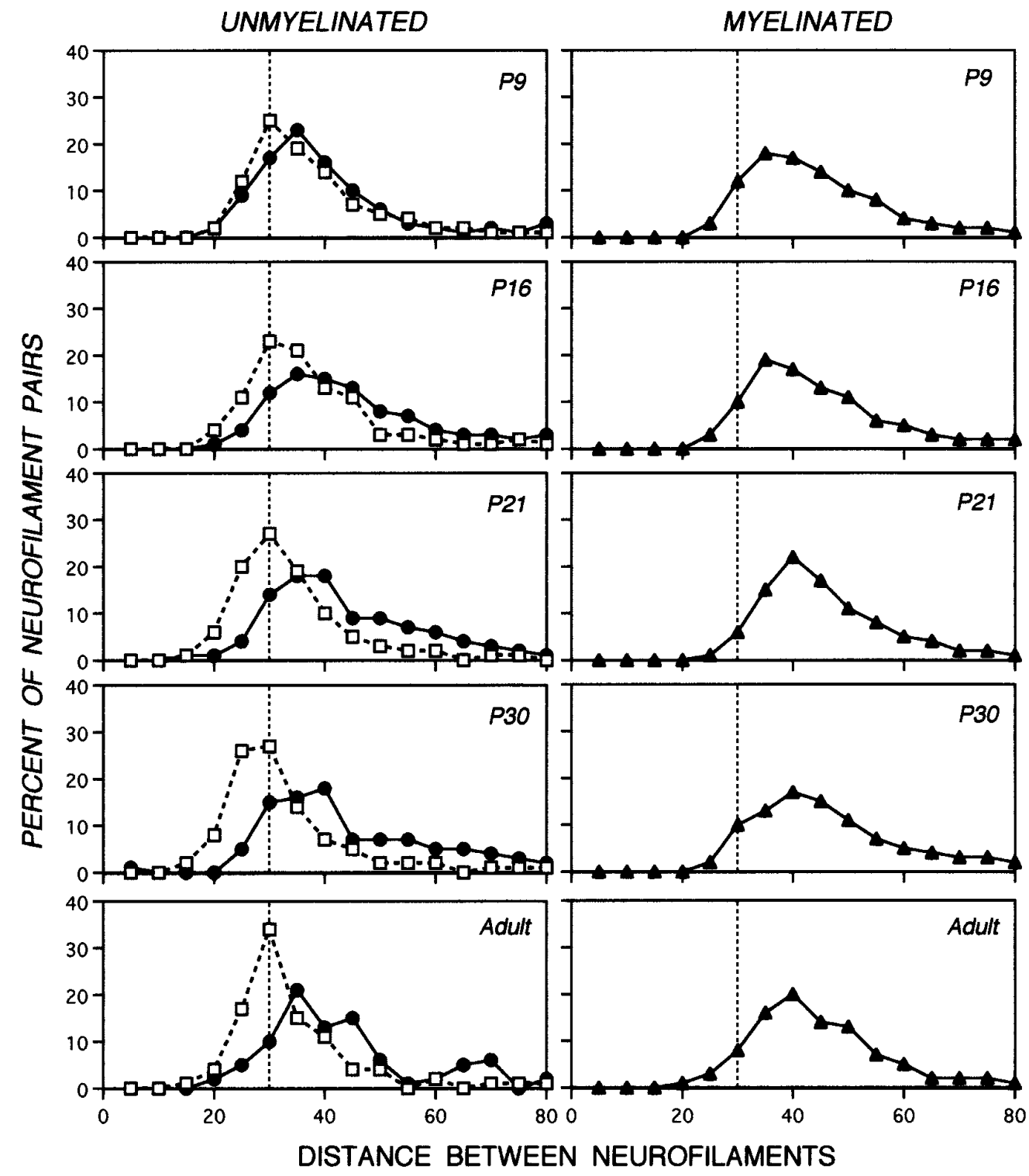

Figure 6. Nearest-neighbor analysis of interneurofilament spacing in axons of developing mice. Data sets contain 273-2150 neurofilament pairs from axons of sizes matched to the caliber distribution representative of the total optic axon population at a given postnatal age. Each data point indicates the percentage of neurofilament pairs that display nearest-neighbor distances within the specified range. The dotted vertical line through the $30 \mathrm{~nm}$ point demarcates the most frequent interneurofilament spacing at the $50 \mu \mathrm{m}$ level to be used as reference for comparison. Analyses of the $700 \mu \mathrm{m}$ level (closed symbols) or $50 \mu \mathrm{m}$ level (open symbols) are depicted. The interneurofilament distance between neurofilaments in P9 and adult myelinated axons does not differ significantly (Tukey-Kramer, $p<$ $0)$. In contrast, the spacing between neurofilaments in the unmyelinated axons at $700 \mu \mathrm{m}$ undergoes a slight but significant increase during development (Tukey-Kramer test, $p>0$ ). been expected at the $50 \mu \mathrm{m}$ level of optic axons as well as the 700 $\mu \mathrm{m}$ level; however, this was not observed. As shown previously in adult mice (Nixon et al., 1994b), local accumulation of neurofilaments must be critically involved in the regional caliber growth seen during development.

The role of interneurofilament spacing in regulating caliber is less clear. In developing unmyelinated axons, neurofilament spacing also is greater distally $(700 \mu \mathrm{m})$ than proximally $(50 \mu \mathrm{m})$ along axons, even though caliber size does not change. These results emphasize that some degree of side-arm extension can occur in the absence of caliber expansion, as recently observed also in a transgenic mouse paradigm (Wong et al., 1995), consistent with the view that local neurofilament accumulation rather than changes in interneurofilament spacing is the critical determinant of axon radial growth. Because neurofilaments in unmyelinated optic axons are relatively few, changes in spacing are expected to have relatively little impact. In unmyelinated axons of shiverer mutants, however, an intermediate degree of increased interneurofilament spacing also had negligible effects on axon caliber, even though neurofilaments were almost as numerous as in normal myelinated axons. In adult mice, myelinated axons at $700 \mu \mathrm{m}$ expand regionally to a caliber that is larger than predicted from the increases of neurofilaments and microtubules. This additional increment of caliber expansion $(\sim 50 \%)$ was attributed to the observed increase in interneurofilament spacing (Nixon et al., 1994a), although regional changes in other structural proteins cannot be excluded as a contributing factor. A similar phenomenon also was seen in this study of axon development. Also supporting a role for neurofilament spacing in caliber expansion under some conditions are observations that optic axons of visually deprived rats are smaller than normal and contained normal numbers of microtubules and neurofilaments, but exhibited reduced interneurofilament distance (Fernandez et al., 1993).

\section{Postnatal axon radial growth requires oligodendroglial signals but not myelin formation}

Although a close relationship between myelination and axon growth under various experimental conditions has been frequently noted (Windebank et al., 1985; Pannese et al., 1988; DeWaegh and Brady, 1990; Cole et al., 1994; Colello et al., 1994; Colello and 
Table 1. Oligodendroglial influences on axon properties

\begin{tabular}{|c|c|c|c|c|c|}
\hline \multirow{2}{*}{$\begin{array}{l}\text { Postnatal } \\
\text { age }\end{array}$} & \multirow{2}{*}{$\begin{array}{l}\text { Axon } \\
\text { parameter }\end{array}$} & \multirow{2}{*}{$\frac{50 \mu \mathrm{m}}{\text { Unmyelinated }}$} & \multicolumn{3}{|l|}{$700 \mu \mathrm{m}$} \\
\hline & & & Unmyelinated & Wrapped & Myelinated \\
\hline \multirow{2}{*}{9} & Area & 101 & 92 & 234 & 426 \\
\hline & MT & 10,323 & 8650 & 13,444 & 20,900 \\
\hline \multirow[b]{2}{*}{16} & Area & 150 & 117 & 201 & 534 \\
\hline & $\mathrm{NF}$ & 19,869 & 11,475 & 23,468 & 55,825 \\
\hline \multirow{3}{*}{21} & Area & 152 & 102 & 232 & 503 \\
\hline & $\mathrm{NF}$ & 20,086 & 12,343 & 34,866 & 51,000 \\
\hline & MT & 16,098 & 13,525 & 21,461 & 29,338 \\
\hline
\end{tabular}

Cross-sectional area and neurofilament and microtubule number are expressed per 1000 axons representative of the total optic axon population.

Schwab, 1994), we found that full-caliber expansion can be achieved without myelin formation. Intermediate degrees of caliber expansion and neurofilament accumulation occurred during the brief period before myelination when axons were ensheathed by oligodendroglial processes. In myelin-deficient mutant mice, in which this transitional state was extended over months rather than hours, oligodendrocyte-wrapped axons achieved the same caliber as the few axons that contained myelin. Direct oligodendrocyte contact was essential to effect radial growth. Increased interneurofilament spacing also was stimulated by the presence of oligodendrocytes, although additional factors also may be important.

The influence of oligodendrocytes on axonal maturation is consistent with evidence that myelin-forming cells elaborate fac- tors that modulate axonal outgrowth (Caroni and Schwab, 1989; Mukhopadhyay et al., 1994; Schwalb et al., 1995), some of which show increased expression after axonal outgrowth and before myelination during a period when some properties of axon membranes are known to change (Lund et al., 1986). Potential targets for oligodendroglial signals include a multiplicity of protein kinases and phosphatases that are believed to regulate phosphorylation of carboxyl terminus domains of neurofilament subunits (Nixon and Sihag, 1991; Lew and Wang, 1995; Shetty et al., 1995). In addition, we cannot exclude indirect effects of oligodendrocyte wrapping, which might trigger axonal events by depriving axons of inhibiting signals from astrocytes or other cells.

Although radial growth clearly depends on extrinsic factors,
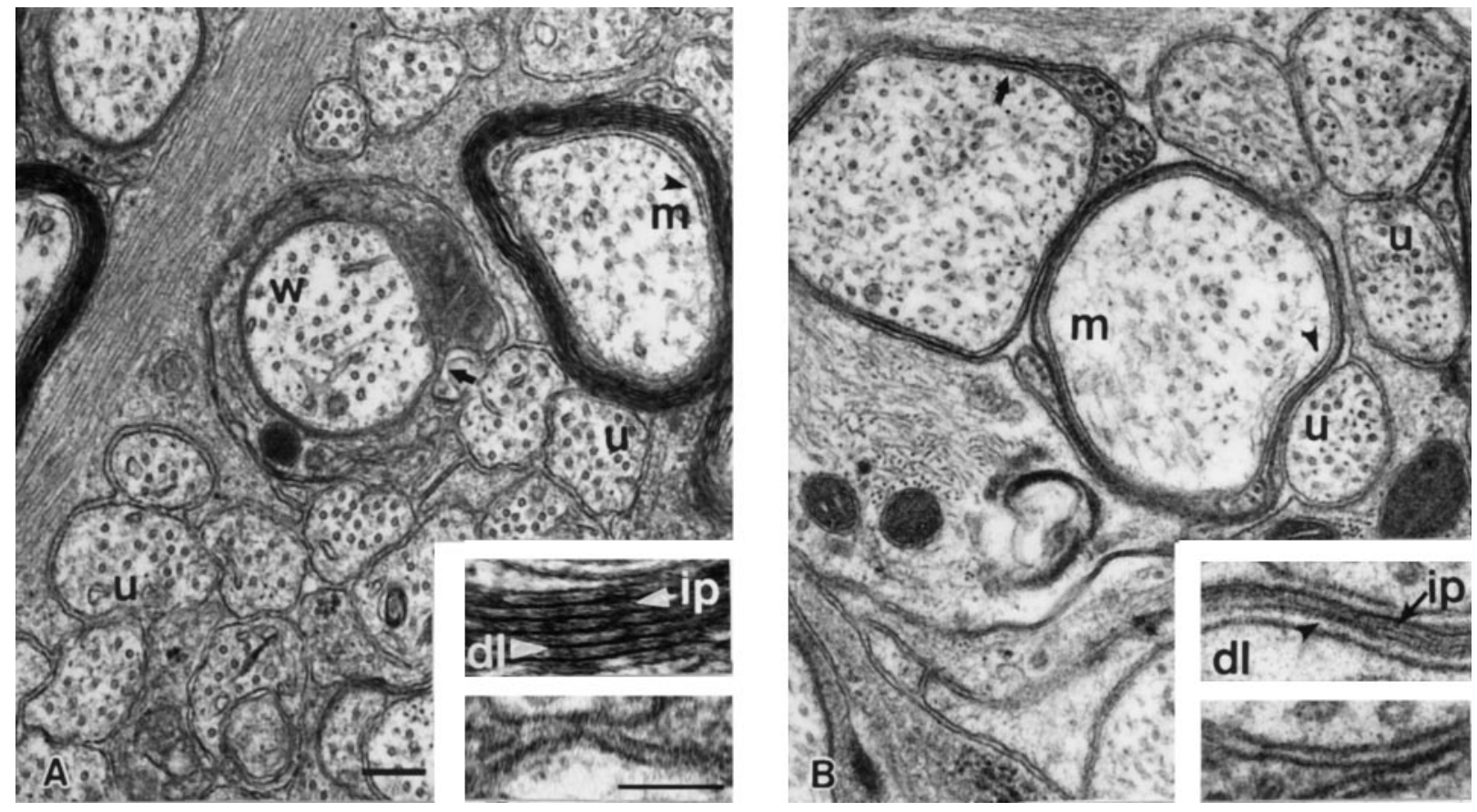

Figure 7. Ultrastructural appearance of representative axonal profiles from normal developing (P21) mice and adult MBP-deficient shiverer mice. Unmyelinated $(u)$, myelinated $(m)$, and oligodendrocyte-wrapped unmyelinated axons $(w)$ from P21 and shiverer optic axons are shown in $A$ and $B$, respectively. Regions shown in the insets are denoted by black arrowheads in $A$ and $B$. High-magnification view of oligodendrocyte-axon interaction in myelinated (top insets) and wrapped (bottom inset) axons. $A$, Myelinated axons from developing optic nerve show both the major dense line (dl; white arrowhead) and intraperiod dense line (ip; white arrow), whereas wrapped axons lack both of these features (bottom inserts). On the other hand, myelinated fibers from MBP-deficient optic nerves (B) show continuous major dense lines ( dl; black arrowhead) but discontinuous intraperiod dense lines (ip; black arrow) (top inset). Scale bars in $A, 0.2 \mu \mathrm{m}$; lower inset, $100 \mu \mathrm{m}$. 


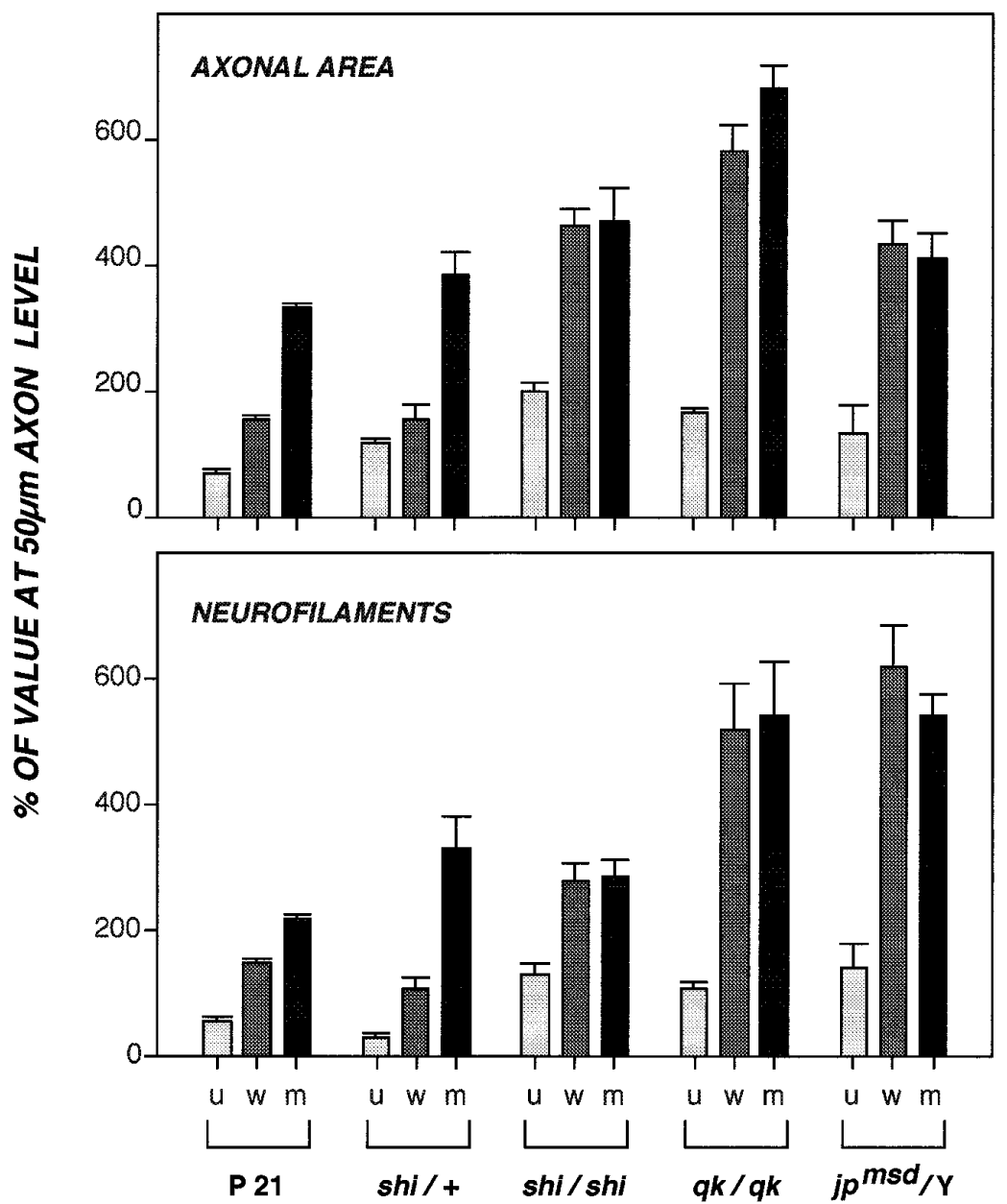

Figure 8. Regional changes in axonal area and neurofilament number in myelin-deficient mutant mice. Crosssectional areas and neurofilament number per 1000 axons of representative caliber sizes were determined at the $50 \mu \mathrm{m}$ level $(n=8062$ or 1016 axons for area or neurofilaments, respectively) and $700 \mu \mathrm{m}$ level $(n=5707$ or 547 axons, respectively) of the optic nerve as described in Figure 3. Data points for unmyelinated $(u)$, oligodendrocyte-wrapped $(w)$, and myelinated $(m)$ populations are expressed as a percentage of the values obtained for these axons analyzed at the $50 \mu \mathrm{m}$ level and their respective SEM. The axonal area and neurofilament number in the oligodendrocytewrapped and myelinated axons in the mutant mice do not differ significantly as shown by the Wilcoxon/Kruskal-Wallis test $(p=0.21-0.73)$ (see Materials and Methods).

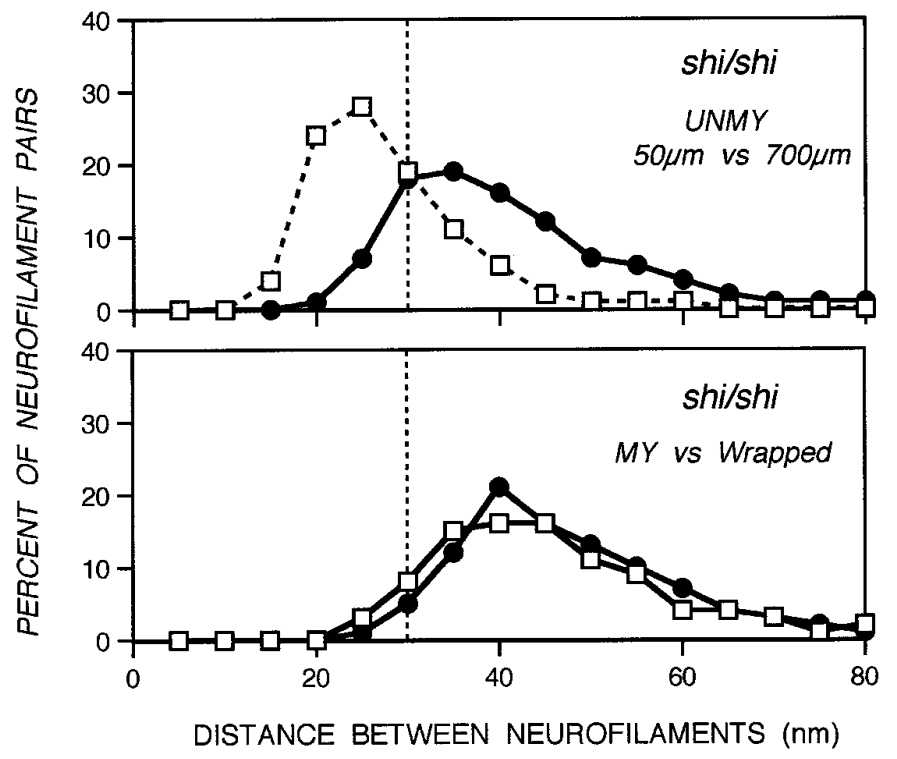

Figure 9. Nearest-neighbor analysis of interneurofilament spacing in axons from myelination mutants. Neurofilament pairs (912-2580) were analyzed from 25 axons representative of the total axonal population for the shiverer mutant at different optic nerve levels. Data points indicate the percentage of neurofilament pairs within a specified distance range from their nearest neighbor. Neurofilaments in axons wrapped by oligodendrocyte processes, but devoid of myelin, display the same interneurofilament spacing as those in myelinated axons (Tukey-Kramer test, $p<0$ ) (see Materials and Methods). how final caliber size is determined is not entirely clear. Even when neurofilaments are few during early development or absent in transgenic or mutant animals, axons exhibit up to 30-fold variation in cross-sectional area (Ohara et al., 1993; Eyer and Peterson, 1994). This degree of caliber variation also was observed in the total population of optic axons at P9, when most axons are unmyelinated. Although a range of cross-sectional areas is observed in these axonal populations, they do not attain mature calibers if devoid of neurofilaments. In addition, neurons can compensate partially for deficiencies of neurofilaments induced by mutations or experimental manipulations by upregulating the production of microtubules and possibly other axonal components to achieve partial caliber expansion (Zhao et al., 1995). Moreover, roles for myelin or other oligodendroglial signals as additional determinants of final caliber are suggested by the fact that incompletely myelinated axons of the myelin-deficient mutant mice actually achieve supranormal caliber growth of varying degrees (R. Nixon, I. Sánchez, L. Hassinger, and P. Paskevich, unpublished data). These observations emphasize, therefore, that establishment of final caliber size requires a combination of intrinsic neuronal mechanisms, multiple extrinsic signaling events, and axon-glial intercommunications. The important role of oligodendroglial signaling identified here may contribute to the understanding of how delayed or deficient oligodendroglial maturation and function may lead to severe cognitive impairment in many developmental nervous disorders and influence neurological recovery in demyelinating diseases. 


\section{REFERENCES}

Barres BA, Raff MC (1993) Proliferation of oligodendrocyte precursor cells depends on electrical activity of axons. Nature 361:258-259.

Campagnoni A (1988) Molecular biology of myelin proteins from the central nervous system. J Neurochem 51:1-14.

Carden MJ, Schlaepfer W, Lee VM-Y (1985) The structure, biochemical properties and immunogenicity of neurofilament peripheral regions are determined by phosphorylation. J Biol Chem 260:9805-9817.

Carden MJ, Trojanowski JQ, Schlaepfer WW, Lee VM-Y (1987) Twostage expression of neurofilament polypeptides during rat neurogenesis with early establishment of adult phosphorylation patterns. J Neurosci 7:3489-3504.

Caroni P, Schwab ME (1989) Codistribution of neurite growth inhibitors and oligodendrocytes in rat CNS: appearance follows nerve fiber growth and precedes myelination. Dev Biol 136:287-295.

Chernoff GF (1981) Shiverer: an autosomal recessive mutant mouse with myelin deficiency. J Hered 71:128.

Cole JS, Messing A, Trojanowski JQ, Lee VM-Y (1994) Modulation of axon diameter and neurofilaments by hypomyelinating Schwann cells in transgenic mice. J Neurosci 14:6956.

Colello RJ, Schwab ME (1994) A role of oligodendrocytes in the stabilization of optic axon number. J Neurosci 14:6446-6452.

Colello RJ, Pott U, Schwab ME (1994) The role of oligodendrocytes and myelin on axon maturation in the developing rat retinofugal pathways. J Neurosci 14:2594-2605.

Dahl D, Crosby CJ, Gardner EE, Bignami A (1986) Delayed phosphorylation of the largest neurofilament protein in rat optic nerve development. J Neurosci Res 15:513-519.

DeWaegh S, Brady ST (1990) Altered slow axonal transport and regeneration in a myelin-deficient mutant mouse: the trembler as an in vivo model for Schwann cell-axon interactions. J Neurosci 10:1855-1865.

DeWaegh SM, Lee VM-Y, Brady ST (1992) Local modulation of neurofilament phosphorylation, axon caliber, and slow axonal transport by myelinating Schwann cells. Cell 68:451-463.

Doolittle DP, Schweikart KM (1977) Myelin deficient, a new neurological mutant in the mouse. J Hered 68:331-332.

Eyer J, Peterson A (1994) Neurofilament-deficient axons and perikaryal aggregates in viable transgenic mice expressing a neurofilament $\beta$-galactosidase fusion protein. Neuron 12:389-405.

Fernández E, Cuenca N, Cerezo JR, DeJuan J (1993) Visual experience during postnatal development determines the size of optic nerve axons. NeuroReport 5:365-367.

Foster RE, Connors BW, Waxman SG (1982) Rat optic nerve: electrophysiological, pharmacological, and anatomical studies during development. Dev Brain Res 3:371-380.

Geisler N, Kaufmann E, Fischer S, Plessman U, Weber K (1983) Neurofilament architecture combines structural principles of intermediate filaments with carboxyl-terminal extensions increasing in size between triplet proteins. EMBO J 2:1295-1302.

Goldstein ME, Sternberger NH, Sternberger LA (1987) Phosphorylation protects neurofilaments against proteolysis. J Neuroimmunol 14:149-160.

Hardy R, Reynolds R (1993) Neuron-oligodendroglial interactions during central nervous system development. J Neurosci Res 36:121-126.

Hoffman PN, Griffin DW, Price DL (1984) Control of axonal caliber by neurofilament transport. J Cell Biol 99:705-714.

Hoffman PN, Griffin JW, Gold BD, Price DL (1985a) Slowing of neurofilament transport and the radial growth of developing nerve fibers. J Neurosci 5:2920-2929.

Hoffman PN, Thompson GW, Griffin JW, Price DL (1985b) Changes in neurofilament transport coincide temporally with alterations in the caliber of axons in regenerating motor fibers. J Cell Biol 101:1332-1340.

Hoffman PN, Cleveland DW, Griffin JW, Landes PW, Cowan NJ, Price DL (1987) Neurofilament gene expression: a major determinant of axonal caliber. Proc Natl Acad Sci USA 84:3472-3476.

Hsieh ST, Sung-Tsang H, Kidd GJ, Crawford TO, Xu Z, Lin W-M, Trapp BD, Cleveland DW, Griffin JW (1994) Regional modulation of neurofilament organization by myelination in normal axons. J Neurosci 14:6392-6401.

Kidd GJ, Hauer PE, Trapp BD (1990) Axons modulate myelin protein messenger RNA levels during central nervous system myelination in vivo. J Neurosci Res 26:409-418.

Lachapelle F, Lapre P, Gansmuller A, Villarroya H, Gumpel M (1990) Patchy myelination pattern in the jimpy mouse brain: immunohistochemical study. Glia 3:375-384.
Lew J, Wang JH (1995) Neuronal cdc 2-like kinase. Trends Biochem Sci 20:33-37.

Lewis SE, Nixon RA (1988) Multiple phosphorylated variants of the high molecular mass subunit of neurofilaments in axons of retinal cell neurons: characterization and evidence for their differential association with stationary and moving neurofilaments. J Cell Biol 107:2689-2701.

Lund RD, Perry VH, Lagenaur SCF (1986) Cell surface changes in the developing optic nerve of mice. J Comp Neurol 247:439-446.

Mata M, Kupina N, Fink DJ (1992) Phosphorylation dependent neurofilament epitopes are reduced at the node of Ranvier. J Neurocytol 21:199-210.

Meier C, MacPike AD (1970) A neurological mutation (msd) of the mouse causing a deficiency of myelin synthesis. Exp Brain Res 10:512-525.

Mukhopadhyay G, Doherty P, Walsh FS, Crocker PR, Filbin MT (1994) A novel role for myelin-associated glycoprotein as an inhibitor of axonal regeneration. Neuron 13:757-767.

Nakagawa T, Chen J, Zhang Z, Kanai Y, Hirokawa N (1995) Two distinct functions of the carboxyl-terminal tail domain of NF-M upon neurofilament assembly: cross-bridge formation and longitudinal elongation of filaments. J Cell Biol 129:411-429.

Nave KA, Schneider A, Readhead C, Griffiths I, Puhlhofer A, Bartholomoma A, Graf S, Kiefer B (1994) Molecular biology and neurogenetics of myelin proteolipid protein. In: A multidisciplinary approach to myelin diseases II (Salvati S, ed), pp 115-126. New York: Plenum.

Nixon RA (1992) Slow axonal transport. Curr Opin Cell Biol 4:8-14.

Nixon RA, Logvinenko KB (1986) Multiple fates of newly synthesized neurofilament proteins: evidence for a stationary neurofilament network distributed nonuniformly along axons of retinal ganglion cell neurons. J Cell Biol 102:647-659.

Nixon RA, Sihag RK (1991) Neurofilament phosphorylation: a new look at regulation and function. Trends Neurosci 14:501-506.

Nixon RA, Lewis SE, Mercken M, Sihag RK (1994a) [ ${ }^{32}$ P]orthophosphate and $\left[{ }^{35} \mathrm{~S}\right]$ methionine label separate pools of neurofilaments with markedly different axonal transport kinetics in mouse retinal ganglion cells in vivo. Neurochem Res 19:1445-1453.

Nixon RA, Paskevich PA, Sihag RK, Thayer CY (1994b) Phosphorylation on carboxyl terminus domains of neurofilament proteins in retinal ganglion cell neurons in vivo: influences on regional neurofilament accumulation, interneurofilament spacing, and axon caliber. J Cell Biol 126:1031-1046.

Notterpek LM, Rome LH (1994) Functional evidence for the role of axolemma in CNS myelination. Neuron 13:473-485.

Ohara O, Gahara Y, Miyake T, Teraoka H, Kitamura T (1993) Neurofilament deficiency in quail caused by nonsense mutation in neurofilament L-gene. J Cell Biol 121:387-395.

Pannese E, Ledda M, Matsuda S (1988) Nerve fibers with myelinated and unmyelinated portion in dorsal spinal root. J Neurocytol 17:693-700.

Pant HC (1988) Dephosphorylation of neurofilament protein enhances their susceptibility to degradation by calpain. Biochem J 256:665-668.

Perry VH, Lund RD (1990) Evidence that the lamina cribrosa prevents intraretinal myelination of retinal ganglion cell axons. J Neurocytol 19:265-272.

Peters A, Vaughn JE (1970) Morphology and development of the myelin sheath. In: Myelination (Davidson A, Peters A, eds), pp 3-79. Springfield: Thomas.

Phillips RJ (1954) Jimpy, a new totally sex-linked gene in the house mouse. Z Verberbungsl 986:322.

Raine CS (1984) Morphology of myelin and myelination. In: Myelin (Morell P, ed), pp 1-50. New York: Plenum.

Reles A, Friede RL (1991) Axonal cytoskeleton at the nodes of Ranvier. J Neurocytol 10:450-458.

Roach A, Boylan K, Horvath S, Prusiner SB, Hood LE (1983) Characterization of cloned cDNA representing rat myelin basic protein: absence of expression in brain of shiverer mutant mouse. Cell 34:799-806.

Sakaguchi T, Okada M, Kitamura T, Kawasaki K (1993) Reduced diameter and conduction velocity of myelinated fibers in the sciatic nerve of a neurofilament-deficient mutant quail. Neurosci Lett 153:65-68.

Schwalb JM, Boulis NM, Gu MF, Winickoff J, Jackson PS, Irwin N, Benowitz LI (1995) Two factors secreted by the goldfish optic nerve induce retinal ganglion cells to regenerate axons in culture. J Neurosci 8:5514-5525.

Shaw G, Weber K (1982) Differential expression of neurofilament triplet proteins in brain development. Nature 298:276-299. 
Shetty KT, Kaech S, Link WT, Jaffe H, Flores CM, Wray S, Pant HC, Beushausen S (1995) Molecular characterization of a neuronal-specific protein that stimulates the activity of cdk 5. J Neurochem 64:1988-1995.

Shine DS, Readhead C, Popko B, Hood L, Sidman RL (1992) Morphometric analysis of normal, mutant, and transgenic CNS: correlation of myelin basic protein expression to myelinogenesis. J Neurochem 58:342-349.

Sidman RL, Dickie MM, Appel SH (1964) Mutant mice (quaking and jimpy) with deficient myelination in the central nervous system. Science 144:309-313.

Takeda S, Okabe S, Funakoshi T, Hirokawa N (1994) Differential dynamics of neurofilament-H protein and neurofilament-L protein in neurons. J Cell Biol 127:173-185.

Valat J, Privat A, Fulcrano J (1988) Experimental modification of postnatal differentiation and fate of glial cells related to axon-glial relationships. Int J Dev Neurosci 6:245-260.
Weidman TA, Kuwabara T (1968) Postnatal development of the rat retina. Arch Ophthalmol 79:470-484.

Windebank AJ, Wood P, Bunge RP, Dyck PJ (1985) Myelination determines the caliber of dorsal root ganglion neurons in culture. J Neurosci 5:1563-1569.

Willard M, Siman C (1983) Modulations of neurofilament axonal transport during the development of rabbit retinal ganglion cells. Cell 35:551-559.

Wong PC, Marszalek J, Crawford TO, Xu Z, Hsieh S-T, Griffin JW, Cleveland DW (1995) Increasing neurofilament subunit NF-M expression reduces axonal NF-H, inhibits radial growth, and results in neurofilamentous accumulation in motor neurons. J Cell Biol 130:1413-1422.

Zhao JX, Ohnishi A, Itakura C, Mizutani M, Yamamoto T, Hojo T, Murai Y (1995) Smaller axon and unaltered numbers of microtubules per axon in relation to number of myelin lamellae of myelinated fibers in the mutant quail deficient in neurofilaments. Acta Neuropathol 89:305-312. 